\title{
Away-from-home eating: nutritional status and dietary intake among Brazilian adults
}

\author{
llana Nogueira Bezerra ${ }^{1, *}$, Eliseu Verly Junior ${ }^{2}$, Rosangela Alves Pereira ${ }^{3}$ \\ and Rosely Sichieri ${ }^{3}$ \\ ${ }^{1}$ Health Science Center, Faculty of Nutrition, University of Fortaleza (UNIFOR), Avenida Washington \\ Soares 1321, sala C07, Coordenação de Nutrição, CEP:60.81 1-905, Fortaleza, CE, Brazil: ${ }^{2}$ Department \\ of Epidemiology, Institute of Social Medicine, State University of Rio de Janeiro, Rio de Janeiro, RJ, Brazil: \\ ${ }^{3}$ Josue de Castro Nutrition Institute, Department of Social Nutrition, Federal University of Rio de Janeiro, \\ Rio de Janeiro, RJ, Brazil
}

Submitted 26 September 2013: Final revision received 29 April 2014: Accepted 6 May 2014: First published online 9 June 2014

\begin{abstract}
Objective: To evaluate the association between eating away from home and BMI and to examine whether dietary intake differs based on the consumption of awayfrom-home food (AFHF).

Design: Data were obtained from the first Brazilian National Dietary Survey, using food records. The association between the percentage of energy provided by foods consumed away from home and BMI status was tested using logistic regression models. The mean percentages of energy provided by protein, fat, saturated fat and free sugars were calculated based on the consumption of foods away from home among AFHF consumers.

Setting: Urban areas of Brazil.

Subjects: Adults ( $n$ 13 736) between 25 and 65 years old.

Results: AFHF was not associated with BMI status. Individuals who consumed AFHF had higher intakes of free sugars away from home than at home and had higher intakes of energy-dense foods than AFHF non-consumers.

Conclusion: Although AFHF consumption was not related to overweight or obesity status, individuals who consumed foods away from home had higher intakes of energy-dense foods. Public health policies should be implemented to help people make healthier food choices away from home.
\end{abstract}

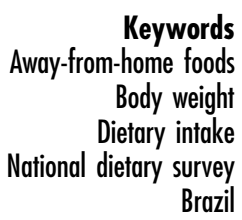

Away-from-home food (AFHF) intake has received attention recently due to the increasing consumption of food outside the home, which may be a factor in the increasing prevalence of overweight and obesity ${ }^{(1)}$. Although excessive weight gain is a result of multiple factors, including genetic, metabolic, socio-economic, behavioural and environmental causes, the consumption of foods away from home has been implicated as a selected behaviour related to overweight and obesity ${ }^{(2-7)}$. Possible mechanisms to explain this relationship include the substantial contribution of AFHF to daily energy intake and the high content of total fat and saturated fat in foods prepared away from home ${ }^{(8)}$.

In Brazil, $50 \%$ of the adult population has a BMI over $25 \mathrm{~kg} / \mathrm{m}^{2}$ and $15 \%$ are obese, representing an increase of $8 \%$ in the prevalence of overweight in 5 years ${ }^{(1)}$. During the same period, expenditures on foods consumed away from home increased by $7 \%^{(2)}$.
One study conducted in a representative sample of Brazilian urban households, using expenditures on foods consumed away from home as a proxy for AFHF consumption, found a positive association between eating out and overweight and obesity among men but not among women ${ }^{(9)}$. Data from the first National Dietary Survey showed that eating away from home positively increased total energy intake in urban areas of Brazil ${ }^{(10)}$.

One important issue that may affect the relationship between eating out and obesity is unhealthy dietary practices within the home food environment. A study in the city of São Paulo, in the south-east of Brazil, investigated the quality of meals consumed at home and away from home and found that only lunch consumed away from home presented lower nutritional quality than lunch consumed at home. The authors concluded that a diet of low nutritional quality is independent of the place of consumption, showing that meals consumed at home also need improvement ${ }^{(11)}$. 
The aim of the present study is to evaluate the association between eating away from home and body weight. In addition, the study aimed to examine whether dietary intake differs based on the consumption of food away from home among AFHF consumers and to compare consumers and non-consumers of AFHF.

\section{Materials and methods}

\section{Study design and study population}

Data were obtained from the first Brazilian National Dietary Survey conducted along with the 2008-2009 Household Budget Survey by the Brazilian Institute of Geography and Statistics. The primary sampling units were selected by systematic sampling with probabilities proportional to size and were stratified by geographic location (urban/rural and five Brazilian geographic areas) and economic level. In the second stage, households were selected by simple random sampling. Thirty per cent of these households were randomly selected to participate in the first Brazilian National Dietary Survey, with a nonresponse rate of $19 \%$. A total of 34003 individuals participated in the dietary survey. Details on the sampling plan and study design are available in a previous publication $^{(12)}$.

Previous analyses have shown that most AFHF intake occurs in urban areas ${ }^{(13)}$. Therefore, for the current paper, only individuals living in urban areas of Brazil were included. Individuals less than 25 years old were excluded because people usually become completely responsible for their own food acquisition after this age. Additionally, individuals aged 65 years or older were excluded because BMI has been found to be less informative of health risks and mortality at this age ${ }^{(14)}$. Pregnant and lactating women ( $n$ 533) were also excluded.

Individuals with missing values for weight and/or height totalled 1084; analyses were conducted either without these values ( $n$ 13736) or with imputed values obtained using the hot deck technique ( $n$ 14820). The methodology used for data imputation can be found in other publications ${ }^{(15,16)}$. Briefly, data were subjected to a system of review and automatic imputation known as Critique and Imputation for Quantitative Data (CIDAQ). This system incorporates multivariate data processing, in which data are evaluated by taking into account the following variables: age, sex, weight, height and household income.

\section{Assessment of away-from-bome food intake}

The definition of AFHF included all foods obtained and consumed away from home. Foods that became a part of the household food supply were not considered AFHF, regardless of the place of purchase or consumption. For example, AFHF did not include foods that were prepared at home but consumed outside the home or ready-to-eat foods that were purchased outside the home but consumed at home. This definition is consistent with its use in other studies ${ }^{(9,10)}$.

Food consumption was assessed by a food record collected on two non-consecutive days; only the first day of intake was included in the present analysis. Individuals recorded their food and beverage intake, excluding water, with as much detail as possible; individuals recorded the time when each food was eaten, the amount eaten and the place where each food was obtained and consumed. Interviewers reviewed all food records, probing for food details and typically forgotten items, and recorded them in a computer database. Food quantities reported using household measures and common portions were transformed into grams or millilitres to estimate the total amount of food consumed. Then, the nutritional composition of the total amount of food consumed was estimated using a Brazilian food composition table specially developed for the survey ${ }^{(17)}$.

\section{Anthropometric measures}

Weight and height were measured by trained interviewers at respondents' households using an electronic portable scale and a wall-mounted stadiometer. Weight was measured to the nearest $100 \mathrm{~g}$ using an electronic portable scale, and height was measured to the nearest $0.1 \mathrm{~cm}$ using a vertical wall-mounted stadiometer. Details of the procedures used can be found in a previous publication $^{(15)}$. BMI was computed as weight ( $\mathrm{kg}$ ) divided by the square of height $\left(\mathrm{m}^{2}\right)$, and the WHO cut-offs were used to classify the respondents: $25 \mathrm{~kg} / \mathrm{m}^{2} \leq \mathrm{BMI}<30 \mathrm{~kg} / \mathrm{m}^{2}$ for overweight and BMI $\geq 30 \mathrm{~kg} / \mathrm{m}^{2}$ for obesity ${ }^{(18)}$.

\section{Sociodemographic variables}

Sociodemographic characteristics included age, sex, household income and years of schooling. Household income included all monetary and non-monetary incomes. Years of schooling were divided into four categories: up to 4 years, between 5 and 9 years, between 10 and 12 years, and 13 years or more.

\section{Statistical analyses}

Descriptive statistics were used to evaluate the differences between AFHF consumers and non-consumers. The $\chi^{2}$ statistic was used for categorical variables, and linear regression models with the consumption of food away from home as the independent variable were used for continuous variables.

The association between the percentage of energy provided by foods consumed away from home and overweight or obese BMI status was tested using logistic regression models. The generalized logit function was used to compare the overweight and obese categories with the reference category (normal weight). The models 
were further adjusted for per capita household income and years of schooling.

The mean percentages of energy provided by protein, fat, saturated fat and free sugars were calculated based on the consumption of foods away from home. Among AFHF consumers, we also compared the percentage of energy from these nutrients provided by at-home and away-fromhome food consumption.

Food categories, representing similar food items in nutritional content or in the way foods are customarily consumed, were created to compare the consumption of specific food groups by place of consumption. Food categories included rice, beans, milk, pizza, deep-fried and baked snacks, sandwiches, sweets and sugar, soft drinks and alcoholic beverages. Rice and beans were included because they represent traditional foods consumed in Brazil ${ }^{(19)}$ and are promoted by the Brazilian Food Guidelines, as well as milk, which was analysed as a contrast to the consumption of soft drinks ${ }^{(20)}$. Alcoholic beverages were also included in the analyses because they are frequently consumed away from home ${ }^{(21,22)}$. The other groups were chosen because of their high energy content and low nutrient density, which are generally considered to contribute to overweight status ${ }^{(23-26)}$. The association between eating away from home (yes/no) and energy consumption from these food categories was tested through linear regression models. These models were adjusted for sex, age and per capita household income (model 1), as well as for total energy intake (model 2).

Statistical analyses were performed using the statistical software package SAS release 9.1.3 (2003). Sample weights were applied to obtain nationally representative estimates, and the stratification and clustering of the design were incorporated into the analyses. This research protocol was approved by the Institute of Social Medicine of the University of the State of Rio de Janeiro (CAAE 0011·0.259.000-11).

\section{Results}

A total of 13736 adults (6179 men and 7557 women) were included in the main analysis. The mean age of the population was 41.7 (SE 0.2 ) years, $38 \%$ were considered overweight and $17 \%$ were classified as obese. The prevalence of AFHF reporting on the first day of intake was $42.7 \%$ (48.8\% among men and $37 \cdot 1 \%$ among women).

Table 1 presents the characteristics of the sample based on the consumption of AFHF. Individuals who consumed foods away from home were younger and had higher income and a higher schooling level. There was no significant difference between non-consumers and consumers of AFHF in prevalence of overweight and obesity among men, whereas among women, the prevalence of overweight and obesity was lower in consumers compared with non-consumers of food away from home.

We excluded 1084 individuals from the sample because they had missing values for weight and/or height. Although these individuals were more likely to be men and had a higher prevalence of AFHF consumption (45.9 v. $42.7 \%, P<0.0001$ ), there were no significant differences in age, income, total energy intake and away-from-home energy intake between them and those with weight and height data. When the values for weight and/or height imputed using the hot deck technique were included, the prevalences of overweight (38\%) and obesity (17\%) remained the same and the association with the consumption of AFHF did not change.

The consumption of foods away from home was not associated with being overweight or obese among men. Among women, a marginal association was found between eating away from home and not being overweight or obese (Table 2).

Individuals who consumed food away from home had lower intakes of protein and higher intakes of total fat, saturated fat and free sugars than non-consumers.

Table 1 Characteristics of the study population (means or percentages, with their standard errors) according to the consumption of food away from home; urban adults ( $n$ 13 736) aged 25-65 years, Brazilian National Dietary Survey 2008-2009

\begin{tabular}{|c|c|c|c|c|c|c|c|c|c|c|}
\hline \multirow[b]{4}{*}{ Characteristic } & \multicolumn{4}{|c|}{ Men } & \multicolumn{5}{|c|}{ Women } & \multirow[b]{4}{*}{$P$ value } \\
\hline & \multicolumn{4}{|c|}{ Consumption of food away from home } & & \multicolumn{4}{|c|}{ Consumption of food away from home } & \\
\hline & \multicolumn{2}{|c|}{ No $(n$ 3318) } & \multicolumn{2}{|c|}{ Yes $(n 2861)$} & \multirow[b]{2}{*}{$P$ value } & \multicolumn{2}{|c|}{ No (n 4929) } & \multicolumn{2}{|c|}{ Yes (n 2628) } & \\
\hline & Mean or $\%$ & $\%$ SE & Mean or $\%$ & SE & & Mean or \% & $\%$ SE & Mean or \% & $\mathrm{SE}$ & \\
\hline Age (years), mean & $43 \cdot 1$ & 0.3 & 38.7 & 0.3 & $<0.0001$ & $44 \cdot 0$ & 0.2 & 39.5 & 0.3 & $<0.0001$ \\
\hline \multicolumn{11}{|l|}{ Years of schooling (\%) } \\
\hline$\leq 4$ years & $37 \cdot 1$ & 1.4 & $20 \cdot 2$ & $1 \cdot 2$ & $<0.0001$ & 35.5 & $1 \cdot 1$ & $19 \cdot 2$ & $1 \cdot 2$ & $<0.0001$ \\
\hline $5-9$ years & 24.0 & 1.2 & 23.7 & 1.3 & & 23.0 & 1.0 & 19.5 & 1.3 & \\
\hline $10-12$ years & $29 \cdot 6$ & 1.4 & $37 \cdot 8$ & 1.6 & & 33.3 & $1 \cdot 1$ & $38 \cdot 2$ & $1 \cdot 7$ & \\
\hline$\geq 13$ years & $9 \cdot 3$ & 0.9 & $18 \cdot 3$ & 1.5 & & 8.2 & 0.6 & 23.2 & 1.5 & \\
\hline \multicolumn{11}{|l|}{ Nutritional status (\%) } \\
\hline Overweight & $42 \cdot 2$ & 1.4 & 43.7 & 1.5 & 0.63 & $34 \cdot 1$ & $1 \cdot 1$ & 29.7 & 1.5 & $<0.0001$ \\
\hline Obesity & $15 \cdot 0$ & 1.0 & 13.7 & 1.0 & & $20 \cdot 8$ & 0.9 & $16 \cdot 1$ & $1 \cdot 1$ & \\
\hline
\end{tabular}


Considering only individuals who consumed foods away from home, the percentage of energy from protein, as well from as fat and saturated fat, was lower away from home

Table 2 Association (odds ratios and $95 \%$ confidence intervals) of being overweight or obese with percentage of energy from foods consumed away from home; urban adults ( $n$ 13736) aged 25-65 years, Brazilian National Dietary Survey 2008-2009

\begin{tabular}{lccccc}
\hline & \multicolumn{2}{c}{ Men } & & \multicolumn{2}{c}{ Women } \\
\cline { 2 - 3 } \cline { 5 - 6 } Model & OR & $95 \% \mathrm{Cl}$ & & OR & $95 \% \mathrm{Cl}$ \\
\hline No adjustment & & & & \\
$\quad$ Normal weight & 1.000 & - & & 1.000 & - \\
$\quad$ Overweight & 1.001 & $0.998,1.004$ & & 0.995 & $0.991,0.998$ \\
$\quad$ Obesity & 0.999 & $0.994,1.003$ & & 0.994 & $0.990,0.998$ \\
Adjusted for per capita household income & and years of schooling \\
Normal weight & 1.000 & - & 1.000 & - \\
$\quad$ Overweight & 1.000 & $0.997,1.003$ & & 0.995 & $0.992,0.999$ \\
$\quad$ Obesity & 0.997 & $0.992,1.002$ & & 0.995 & $0.991,0.999$ \\
\hline
\end{tabular}

than at home, but the contribution of free sugars to energy intake was higher away from home (Table 3).

The mean energy intake from specific food groups based on the consumption of foods away from home is shown in Table 4. On average, individuals who consumed AFHF had lower total intakes of rice, beans and milk and higher total intakes of energy-dense foods such as deepfried and baked snacks, sweets and sugar, and soft drinks than non-consumers. The total consumption of alcoholic beverages was also higher among AFHF consumers than non-consumers. After controlling for sex, age, per capita household income and total energy intake, these differences remained.

\section{Discussion}

In a large sample of 13736 adults living in urban areas of Brazil, no association between eating away from home

Table 3 Percentage of energy from protein, fat, saturated fat and free sugars (means and their standard errors) according to the consumption of foods away from home; urban adults ( $n$ 13 736) aged 25-65 years, Brazilian National Dietary Survey 2008-2009

\begin{tabular}{|c|c|c|c|c|c|c|c|c|}
\hline & \multicolumn{8}{|c|}{ Consumption of food away from home } \\
\hline & & & & & & & & \\
\hline & \multicolumn{2}{|c|}{ No } & \multicolumn{2}{|c|}{ Total } & \multicolumn{2}{|c|}{ At home } & \multicolumn{2}{|c|}{ Away from home } \\
\hline & Mean & SE & Mean & SE & Mean & SE & Mean & SE \\
\hline \multicolumn{9}{|l|}{ Men } \\
\hline Energy from protein (\%) & $17 \cdot 7$ & 0.2 & $17 \cdot 1^{*}$ & 0.2 & $16 \cdot 3$ & 0.2 & $15.4 \dagger$ & 0.4 \\
\hline Energy from fat (\%) & $27 \cdot 1$ & 0.2 & $27 \cdot 4$ & 0.2 & $27 \cdot 4$ & 0.3 & $25.4 \dagger$ & 0.5 \\
\hline Energy from saturated fat (\%) & $9 \cdot 1$ & 0.1 & $9 \cdot 4^{*}$ & 0.1 & 9.9 & 0.1 & $8.7 \dagger$ & 0.2 \\
\hline Energy from free sugar (\%) & $16 \cdot 3$ & 0.3 & $18 \cdot 9^{*}$ & 0.3 & $20 \cdot 6$ & 0.5 & $29 \cdot 1 \dagger$ & 1.0 \\
\hline \multicolumn{9}{|l|}{ Women } \\
\hline Energy from protein (\%) & $16 \cdot 8$ & 0.1 & $16 \cdot 3^{*}$ & 0.2 & $15 \cdot 5$ & 0.2 & $14 \cdot 6 \dagger$ & 0.3 \\
\hline Energy from fat (\%) & $26 \cdot 8$ & 0.2 & $27 \cdot 7^{\star}$ & 0.3 & $27 \cdot 2$ & 0.3 & $26 \cdot 2 \dagger$ & 0.4 \\
\hline Energy from saturated fat (\%) & $9 \cdot 2$ & 0.1 & $9 \cdot 9^{*}$ & 0.2 & $10 \cdot 1$ & 0.2 & $9.2 \dagger$ & 0.2 \\
\hline Energy from free sugar (\%) & $20 \cdot 0$ & 0.3 & $22 \cdot 9^{*}$ & 0.4 & $24 \cdot 0$ & 0.5 & $30.7 \dagger$ & 0.8 \\
\hline
\end{tabular}

${ }^{*} P \leq 0.01$ for comparison between non-consumers and away-from-home food consumers.

$\dagger P \leq 0.01$ for the comparison between at-home and away-from-home nutrient consumption among away-from-home food consumers.

Table 4 Consumption of energy from specific food groups ( $\mathrm{kJ}$; means and their standard errors) according to the consumption of foods away from home and regression coefficients ( $\beta$ coefficients and $P$ values) comparing consumers with non-consumers of food away from home; urban adults $(n$ 13736) aged 25-65 years, Brazilian National Dietary Survey 2008-2009

\begin{tabular}{|c|c|c|c|c|c|c|c|c|}
\hline \multirow[b]{3}{*}{ Food group } & \multicolumn{4}{|c|}{ Consumption of food away from home } & & & & \\
\hline & \multicolumn{2}{|c|}{ No } & \multicolumn{2}{|c|}{ Yes } & \multicolumn{2}{|c|}{ Model $1^{\star}$} & \multicolumn{2}{|c|}{ Model 2† } \\
\hline & Mean & SE & Mean & SE & $\beta$ & $P$ & $\beta$ & $P$ \\
\hline Rice & $975 \cdot 3$ & $14 \cdot 6$ & $956 \cdot 9$ & $18 \cdot 0$ & $-12 \cdot 3$ & 0.02 & -22.4 & $<0.0001$ \\
\hline Beans & $858 \cdot 1$ & $18 \cdot 8$ & $818 \cdot 0$ & $21 \cdot 8$ & -14.7 & 0.03 & $-26 \cdot 2$ & $<0.0001$ \\
\hline Milk & 231.4 & $10 \cdot 5$ & $230 \cdot 5$ & $11 \cdot 7$ & $-5 \cdot 2$ & 0.18 & $-8 \cdot 1$ & 0.04 \\
\hline Sweets and sugars & $194 \cdot 1$ & $12 \cdot 6$ & $361 \cdot 1$ & $31 \cdot 8$ & $37 \cdot 5$ & $<0.0001$ & $24 \cdot 2$ & 0.0002 \\
\hline Pizza & $46 \cdot 9$ & $10 \cdot 5$ & $92 \cdot 0$ & $15 \cdot 1$ & $6 \cdot 2$ & 0.16 & $2 \cdot 0$ & 0.63 \\
\hline Deep-fried and baked snacks & $60 \cdot 2$ & $7 \cdot 1$ & $207 \cdot 1$ & $15 \cdot 1$ & $33 \cdot 1$ & $<0.0001$ & $30 \cdot 6$ & $<0.0001$ \\
\hline Sandwiches & $85 \cdot 8$ & $10 \cdot 5$ & $229 \cdot 7$ & $16 \cdot 3$ & 29.5 & $<0.0001$ & $27 \cdot 3$ & $<0.0001$ \\
\hline Soft drinks & $104 \cdot 2$ & $6 \cdot 7$ & $218 \cdot 8$ & $9 \cdot 2$ & $21 \cdot 2$ & $<0.0001$ & $18 \cdot 3$ & $<0.0001$ \\
\hline Alcoholic beverages & $47 \cdot 3$ & $7 \cdot 1$ & $202 \cdot 5$ & $23 \cdot 8$ & $32 \cdot 6$ & $<0.0001$ & $25 \cdot 4$ & $<0.0001$ \\
\hline
\end{tabular}

${ }^{*}$ Adjusted for sex, age and per capita household income.

†Adjusted for sex, age, per capita household income and total energy intake. 
and being overweight or obese was observed among men, and a marginal negative association was observed among women.

In a previous study also conducted among Brazilian adults living in urban areas of Brazil, a positive association was found between eating out of the home and overweight and obesity among men ${ }^{(9)}$. This difference could be explained by the way food away from home was assessed. Bezerra and Sichieri ${ }^{(9)}$ used expenditures on foods consumed away from home in a $7 \mathrm{~d}$ period, which could have increased the probability of identifying substantial AFHF consumers.

On the other hand, our finding of no association between eating away from home and BMI among men is consistent with the findings of a large study conducted with 34974 Spanish adults, in which no association was found between having any of the main meals away from home and obesity ${ }^{(7)}$. Additionally, in a representative national sample of Australian adults (1277 men and 1585 women), no association was found between consuming takeaway food twice weekly or more and overweight or obesity among men ${ }^{(27)}$.

Our finding of a negative association between AFHF and obesity among women is consistent with a study conducted with 1070 Korean housewives, in which women who ate outside the home at moderate levels had lower obesity rates ${ }^{(28)}$.

The positive association between eating out of the home and obesity is more frequent when fast-food restaurants are analysed separately from full-service restaurants. Among young US adults, greater fast food (but not restaurant food) consumption was associated with higher $\mathrm{BMI}^{(29-32)}$. However, the association between eating out and body weight is controversial; other studies have suggested that the consumption of food away from home is positively related to body weight, BMI or the prevalence of overweight and/or obesity ${ }^{(5,33)}$, while different ones have described no association ${ }^{(7,34,35)}$.

A more conservative definition, in which individuals were considered substantial away-from-home eaters if they reported more than $25 \%$ of their total energy intake from away-from-home occasions, was previously used by other researchers ${ }^{(22,23)}$. When applying this definition, no association was detected between eating out and BMI among European adults ${ }^{(18)}$, and no significant association with BMI was found in the present study (data not shown).

Although no association was found between eating away from home and BMI, the impact of AFHF on nutrient intake and daily consumption of specific food groups was substantial. Individuals who consumed food away from home presented lower intakes of energy as protein and higher intakes of energy as total fat, saturated fat and free sugars than non-consumers.

These findings corroborate the results of other studies in which high consumers of AFHF presented higher percentage of energy from fat ${ }^{(35-37)}$. The consumption of food away from home also contributed to more fat and sugar intake among a large sample of European adults (35-70 years old); however, there was no difference between macronutrient contributions to energy intake when at-home eating was compared with out-of-home eating, particularly in northern European countries ${ }^{(38)}$. One study conducted among Irish adults reported a lower energy contribution from fat consumed out of the home compared with fat consumed at home ${ }^{(39)}$.

When evaluating specific food groups, individuals who consumed AFHF had lower total intakes of rice, beans and milk and higher total intakes of energydense foods such as deep-fried and baked snacks, sweets and sugar, and soft drinks than non-consumers. The total consumption of alcoholic beverages was also higher among away-from-home consumers than nonconsumers.

The consumption of sweets, soft drinks and alcoholic beverages was previously identified as more likely to occur away from home ${ }^{(22,23,36,40)}$. In a recent systematic review, Lachat and colleagues concluded that foods consumed away from home are positively associated with higher fat intake and lower nutrient quality ${ }^{(8)}$. It is worth noting that previous analyses of the present data showed that eating out of the home is positively associated with total energy intake, but the magnitude of this association was very low ${ }^{(10)}$. In the case of possible bias in our results, it would probably be due to underestimation since those individuals who eat away from home less frequently may be classified as out-of-home non-eaters.

The absence of an association between AFHF intake and overweight or obesity can also be explained by the cross-sectional design of the study, which is prone to reverse causality. Obese individuals might eat less away from home to better control their energy intake and prevent weight gain. Additionally, weight gain is an ongoing process that is not properly captured under crosssectional analysis. Also, food records were used to assess AFHF intake, which is prone to alter dietary behaviour by decreasing the amount or quality of intake, resulting in dietary misreporting of food intake ${ }^{(41)}$.

We defined AFHF based on the place of purchase and consumption of food; foods that went into the household food supply, such as delivery meals or takeaway foods that were consumed at home, were not considered to be AFHF. With this definition, AFHF better represent an individual decision to eat that food as opposed to at-home foods, which are usually available for all members of the household. However, this definition does not allow the differentiation of food between fast-food restaurants, full-service restaurants or work cafeterias. Naska et al. found that eating at work, but not at restaurants, may not contribute to overweight among men ${ }^{(5)}$. Larson and colleagues described a higher intake of vegetables among frequent full-service restaurant users but not among fastfood restaurant users ${ }^{(31)}$. 


\section{Conclusion}

In conclusion, our findings indicate that eating away from home is not associated with obesity among men and is negatively associated with overweight and obesity among women from urban areas of Brazil. However, AFHF consumers had lower intakes of protein and higher intakes of total fat, saturated fat and free sugars than non-consumers and higher intakes of deep-fried and baked snacks, sweets and sugar, and soft drinks. Therefore, public health policies should be implemented to help people make healthier food choices away from home.

\section{Acknowledgements}

Financial support: The Brazilian National Dietary Survey was funded by the Brazilian Ministry of Health. I.N.B. received a fellowship from the Brazilian Federal Agency for the Improvement of Higher Education (CAPES; Process no. 6748-10-4). The Brazilian Ministry of Health and CAPES had no role in the design, analysis or writing of this article. Conflict of interest: None. Authorship: R.S. and R.A.P. served as principal investigators, conceptualized the study and drafted the article. E.V. Jr assisted with study design and analyses as well as article writing and review. I.N.B. participated in the quality control of the data, data analysis and article writing and review. Ethics of human subject participation: This research protocol was approved by the University of the State of Rio de Janeiro (CAAE 0011·0·259-000-11).

\section{References}

1. Bezerra IN, Curioni C \& Sichieri R (2012) Association of eating out of home and body weight. Nutr Rev 70, 65-79.

2. Popkin BM, Adair LS \& Ng SW (2012) Global nutrition transition and the pandemic of obesity in developing countries. Nutr Rev 70, 3-21.

3. Prentice AM \& Jebb SA (2003) Fast foods, energy density and obesity: a possible mechanistic link. Obes Rev $\mathbf{4}$, 187-194.

4. Rosenheck R (2008) Fast food consumption and increased caloric intake: a systematic review of a trajectory towards weight gain and obesity risk. Obes Rev 9, 535-547.

5. Naska A, Orfanos P, Trichopoulou A et al. (2011) Eating out, weight and weight gain. A cross-sectional and prospective analysis in the context of the EPIC-PANACEA study. Int $J$ Obes (Lond) 35, 416-426.

6. Bes-Rastrollo M, Basterra-Gortari FJ, Sanchez-Villegas A et al. (2009) A prospective study of eating away-from-home meals and weight gain in a Mediterranean population: the SUN (Seguimiento Universidad de Navarra) cohort. Public Health Nutr 13, 1356-1363.

7. Marin-Guerrero AC, Gutierrez-Fisac JL, Guallar-Castillon P et al. (2008) Eating behaviours and obesity in the adult population of Spain. Br J Nutr 100, 1142-1148.

8. Lachat C, Nago E, Verstraeten R et al. (2012) Eating out of home and its association with dietary intake: a systematic review of the evidence. Obes Rev 13, 329-346.
9. Bezerra IN \& Sichieri R (2009) Eating out of home and obesity: a Brazilian nationwide survey. Public Health Nutr 12, 2037-2043.

10. Bezerra IN, de Moura Souza A, Pereira RA et al. (2013) Contributions of foods consumed away from home to energy intake in Brazilian urban areas: the 2008-9 Nationwide Dietary Survey. Br J Nutr 109, 1276-1283.

11. Gorgulho BM, Fisberg RM \& Marchioni DM (2013) Nutritional quality of major meals consumed away from home in Brazil and its association with overall diet quality. Prev Med 57, 98-101.

12. Instituto Brasileiro de Geografia e Estatística (2011) Consumer Expenditure Survey 2008-2009: Analysis of the Personal Food Consumption in Brazil. Rio de Janeiro: IBGE (in Portuguese).

13. Bezerra IN, Souza Ade M, Pereira RA et al. (2013) Consumption of foods away from home in Brazil. Rev Saude Publica 47, Suppl. 1, 200S-211S.

14. Douketis JD, Paradis G, Keller H et al. (2005) Canadian guidelines for body weight classification in adults: application in clinical practice to screen for over-weight and obesity and to assess disease risk. CMAJ 172, 995-998.

15. Instituto Brasileiro de Geografia e Estatística (2010) Consumer Expenditure Survey 2008-2009: Anthropometry and Nutritional Status of Children, Teenagers and Adults in Brazil. Rio de Janeiro: IBGE (in Portuguese).

16. Andridge RR \& Little RJA (2010) A review of hot deck imputation for survey non-response. Int Stat Rev 78, 40-64.

17. Instituto Brasileiro de Geografia e Estatística (2011) Consumer Expenditure Survey 2008-2009: Table of Nutritional Composition of Foods Consumed in Brazil. Rio de Janeiro: IBGE (in Portuguese).

18. World Health Organization (1995) Physical Status: The Use and Interpretation of Anthropometry. Report of a WHO Expert Committee. WHO Technical Report Series no. 854. Geneva: WHO.

19. Marchioni DM, Claro RM, Levy RB et al. (2011) Patterns of food acquisition in Brazilian households and associated factors: a population-based survey. Public Health Nutr 14, $1586-1592$.

20. Ministério da Saúde, Secretária de Atenção à Saúde, Departamento de Atenção Básica (2006) Guia Alimentar para a População Brasileira: Promovendo a Alimentação Saudável. Brasília: Ministério da Saúde.

21. Orfanos P, Naska A, Trichopoulos D et al. (2007) Eating out of home and its correlates in 10 European countries. The European Prospective Investigation into Cancer and Nutrition (EPIC) study. Public Health Nutr 10, 1515-1525.

22. Vandevijvere S, Lachat C, Kolsteren P et al. (2009) Eating out of home in Belgium: current situation and policy implications. Br J Nutr 102, 921-928.

23. Malik VS, Popkin BM, Bray GA et al. (2010) Sugarsweetened beverages, obesity, type 2 diabetes mellitus, and cardiovascular disease risk. Circulation 121, 1356-1364.

24. Johnson RK, Appel LJ, Brands M et al. (2009) Dietary sugars intake and cardiovascular health: a scientific statement from the American Heart Association. Circulation 120, 1011-1020.

25. Guallar-Castillon P, Rodriguez-Artalejo F, Fornes NS et al. (2007) Intake of fried foods is associated with obesity in the cohort of Spanish adults from the European Prospective Investigation into Cancer and Nutrition. Am J Clin Nutr 86, 198-205.

26. Taveras EM, Berkey CS, Rifas-Shiman SL et al. (2005) Association of consumption of fried food away from home with body mass index and diet quality in older children and adolescents. Pediatrics 116, 518-524.

27. Smith KJ, McNaughton SA, Gall SL et al. (2009) Takeaway food consumption and its associations with diet quality and 
abdominal obesity: a cross-sectional study of young adults. Int J Behav Nutr Phys Act 6, 29.

28. Choi MK, Kim TY \& Yoon J-S (2011) Does frequent eating out cause undesirable food choices? Association of food away from home with food consumption frequencies and obesity among Korean housewives. Ecol Food Nutr 50, 263-280.

29. Duffey KJ, Gordon-Larsen P, Jacobs DR Jr et al. (2007) Differential associations of fast food and restaurant food consumption with 3-y change in body mass index: the Coronary Artery Risk Development in Young Adults Study. Am J Clin Nutr 85, 201-208.

30. Jeffery RW, Baxter J, McGuire M et al. (2006) Are fast food restaurants an environmental risk factor for obesity? Int $J$ Behav Nutr Phys Act 3, 2.

31. Larson N, Neumark-Sztainer D, Laska MN et al. (2011) Young adults and eating away from home: associations with dietary intake patterns and weight status differ by choice of restaurant. J Am Diet Assoc 111, 1696-1703.

32. Anderson B, Rafferty AP, Lyon-Callo S et al. (2011) Fast-food consumption and obesity among Michigan adults. Prev Chronic Dis 8, A71.

33. Ko GT, Chan JC, Tong SD et al. (2007) Associations between dietary habits and risk factors for cardiovascular diseases in a Hong Kong Chinese working population - the 'Better Health for Better Hong Kong' (BHBHK) health promotion campaign. Asia Pac J Clin Nutr 16, 757-765.

34. French SA, Harnack LJ, Toomey TL et al. (2007) Association between body weight, physical activity and food choices among metropolitan transit workers. Int J Behav Nutr Phys Act 4, 52 .

35. Burns C, Jackson M, Gibbons C et al. (2002) Foods prepared outside the home: association with selected nutrients and body mass index in adult Australians. Public Health Nutr $\mathbf{5}$, 441-448.

36. Kearney JM, Hulshof KF \& Gibney MJ (2001) Eating patterns temporal distribution, converging and diverging foods, meals eaten inside and outside of the home - implications for developing FBDG. Public Health Nutr 4, 693-698.

37. van't Riet H, den Hartog AP \& van Staveren WA (2002) Nonhome prepared foods: contribution to energy and nutrient intake of consumers living in two low-income areas in Nairobi. Public Health Nutr 5, 515-522.

38. Orfanos P, Naska A, Trichopoulou A et al. (2009) Eating out of home: energy, macro- and micronutrient intakes in 10 European countries. The European Prospective Investigation into Cancer and Nutrition. Eur J Clin Nutr 63, Suppl. 4, S239-S262.

39. O'Dwyer NA, Gibney MJ, Burke SJ et al. (2005) The influence of eating location on nutrient intakes in Irish adults: implications for developing food-based dietary guidelines. Public Health Nutr 8, 258-265.

40. Bezerra IN \& Sichieri R (2010) Characteristics and spending on out-of-home eating in Brazil. Rev Saude Publica 44, 221-229.

41. Willett WC (1998) Nutritional Epidemiology. New York: Oxford University Press. 